\title{
НОВЫЕ МЕДИА
}

NEW MEDIA

DOI 10.22363/2312-9220-2021-26-2-262-275

УДК 070.431.2

Научная статья / Research article

\section{Развитие научно-популярной журналистики в условиях кросс-медиа}

\author{
Л.К. Лободенко $\mathbb{D}^{\otimes}$, Е.В. Давлетшина \\ Южно-Уральский государственный университет \\ (наииональный исследовательский университет), \\ Российская Федерация, 454080, Челябинск, пр-кт имени В.И. Ленина, д. 76 \\ lobodenkolk@susu.ru
}

\begin{abstract}
Аннотация. Развитие информационно-коммуникативных технологий и цифровизация медиапространства создают новые возможности для популяризации научного знания. Существует потребность в изучении научно-популярной журналистики как деятельности, активно осваивающей мультимедийный сетевой формат и различные каналы дистрибуции медиаконтента. Цель работы - анализ особенностей развития в интернете научно-популярной журналистики в условиях кросс-медиа. В исследовании использовались общенаучные методы (анализ и синтез), метод изучения документов с элементами контент-анализа, сравнительный метод, включающий сопоставление различных типов контента, а также данные сервисов аналитики социальных сетей и мессенджеров. Изучены медиаканалы и способы продвижения медиаконтента, его идейнотематические и структурные характеристики, особенности трансформации медиатекста интернет-СМИ научно-популярной тематики на базе Nplus1.ru и Naked-science.ru. Установлено, что вовлечение аудитории в исследуемых интернет-СМИ осуществляется за счет дифференцированного кросс-медийного присутствия, использования процессов рерайтинга и репостинга. Особое внимание было уделено сравнительному анализу медиаконтента официальных сайтов, аккаунтов в социальной сети «ВКонтакте» и мессенджера Telegram.
\end{abstract}

Ключевые слова: медиапространство, научно-популярная журналистика, кроссмедиа, репостинг, рерайтинг, социальные сети, медиаконтент, медиатекст

Заявление о конфликте интересов. Авторы заявляют об отсутствии конфликта интересов.

(C) Лободенко Л.К., Давлетшина Е.В., 2021

(c) (i) This work is licensed under a Creative Commons Attribution 4.0 International License https://creativecommons.org/licenses/by/4.0/ 
История статьи: поступила в редакцию 8 января 2021 г.; принята к публикации 12 марта 2021 г.

Для цитирования: Лободенко Л.К., Давлетшина Е.В. Развитие научно-популярной журналистики в условиях кросс-медиа // Вестник Российского университета дружбы народов. Серия: Литературоведение. Журналистика. 2021. Т. 26. № 2. С. 262-275. http://dx.doi.org/10.22363/2312-9220-2021-26-2-262-275

\title{
Development of Popular Science Journalism in the Cross-Media Context
}

\author{
Lidia K. Lobodenko $\mathbb{D}^{\circledR}$, Elena V. Davletshina \\ South Ural State University (National Research University), \\ 76 Prospekt Lenina, Chelyabinsk, 454080, Russian Federation \\ $\checkmark$ lobodenkolk@susu.ru
}

\begin{abstract}
The development of information and communication technologies and the digitalization of the media space create new opportunities for the popularization of scientific knowledge. There is an objective need to study popular science journalism as an activity that develops a multimedia network format and various media content distribution channels. The work is aimed at analyzing the features of the development of popular science journalism on the Internet in the context of cross-media. The study employed general scientific methods (analysis and synthesis), a method of studying documents with elements of content analysis, a comparative method that includes a comparison of different types of content, as well as data from social network and messenger analytics services. The authors studied media channels and ways to promote media content, its ideological, thematic, and structural characteristics, the features of its transformation on high citation index rating's scientific-oriented platforms Nplus1.ru and Naked-science.ru. As a result of the conducted research, it was discovered that the audience involved in the studied online media is carried out through a differentiated crossmedia presence, the use of rewriting, and reposting processes. Particular attention was focused on the comparative analysis of the media content of official websites, accounts in the social network VKontakte, and Telegram messenger.
\end{abstract}

Keywords: media space, popular science journalism, cross-media, reposting, rewriting, social media, media content, media text

Conflicts of interest. The authors declare that there is no conflict of interest.

Article history: submitted January 8, 2021; revised February 11, 2021; accepted March 12, 2021.

For citation: Lobodenko, L.K., \& Davletshina, E.V. (2021). Development of popular science journalism in the cross-media context. RUDN Journal of Studies in Literature and Journalism, 26(2), 262-275. (In Russ.) http://dx.doi.org/10.22363/2312-9220-2021-26-2-262-275

\section{Введение}

Современные средства массовой информации в условиях развития информационно-коммуникативных технологий и цифровизации стремительно меняются. Влиянию главным образом подвергаются процессы создания, обработки и распространения контента. С начала XXI века активно разви- 
ваются интернет-СМИ научно-популярного профиля, а научно-популярная журналистика обрела особую актуальность, о чем свидетельствует увеличение медиаресурсов, специализирующихся на освещении научных тем: интернетверсии традиционных журналов и телеканалов; сетевые издания; разделы о науке информационных агентств; агрегаторы научных новостей; группы в соцсетях и т. д. Создание и дистрибуция медиаконтента осуществляется в условиях кросс-медиа и изменения среды пользовательской коммуникации, что вызвало необходимость переосмысления описываемого явления.

Проблемы научно-популярной журналистики в традиционных СМИ изучены достаточно глубоко: осознание природы и предназначения научнопопулярных СМИ [1], развитие научно-популярного знания [2; 3], научнопопулярная журналистика как направление деятельности [4-6]. Есть работы по измерению эффективности контента цифровых медиа [7], в том числе функционала научно-популярной журналистики [8-10], но не изученными остаются кросс-медийные решения дистрибуции научно-популярного медиаконтента, чему и посвящена данная статья.

Для достижения цели необходимо изучить медиаканалы и способы продвижения медиаконтента, его идейно-тематические и структурные характеристики, особенности трансформации медиатекста. Ключевые термины - это «научно-популярная журналистика», «кросс-медиа», «репостинг», «рерайтинг».

Предметом научно-популярной журналистики являются продукты научной деятельности: научные знания, сфера их использования, а также отношения науки и общества, науки и человека (см. [11]), а также «адаптация научных знаний для массового читателя» [12]. Данный подход выбран как основа для исследования.

При анализе интернет-СМИ [13-17] базовым становится термин «кроссмедиа». Под «кросс-медиа» понимают передачу одного и того же (или близкого по смыслу) контента с помощью разных медийных источников (различных СМИ, мобильных устройств и т. д.) (см. [18]. Кроссмедийность «это подход к распространению контента по разным медиаплатформам, преимущественно цифровым» (см. [19]). Г. Хейс выделяет четыре уровня кросс-медиа: Cross-media 1.0 - Pushed (выдвигать, толкать); Cross-media 2.0 Extras (дополнительная стоимость); Cross-media 3.0 - Bridges (мосты); Crossmedia 4.0 - Experiences (опыт) [17].

Кроссмедийность предполагает работу одновременно на нескольких медиаплощадках (сайт, социальные сети, ТВ и т. д.) Вовлечение аудитории происходит за счет дифференцированного представления медиатекста как единой истории. Медиаконтент должен быть релевантен каналу его трансляции и интересен аудитории. Особое значение в этом случае приобретают процессы репостинга и рерайтинга.

Под репостом понимается «копирование какого-либо сообщения (с помощью специальных команд) с одного ресурса на другой с обязательной ссылкой на первоисточник» (см. [20]), а сам процесс копирования сообщения с указанием ссылки на первоисточник называется репостингом. Кросспостинг - намеренная публикация одной и той же информации сразу на нескольких интернет-ресурсах с целью искусственного увеличения количества ссылок на размещенное сообщение. Кросспостинг (автоматическое, полуав- 
томатическое или ручное дублирование публикации с основного ресурса) является самым распространенным способом дистрибуции медиаконтента, так как не требуется больших затрат времени. При этом генерируется ссылочная масса, что положительным образом сказывается на тематическом индексе цитирования и позиции материала в поисковых выдачах.

С целью повышения востребованности распространяемого контента СМИ используется рерайт или рерайтинг, под которым понимается переписывание какого-либо исходного текста с целью получения уникального текста, идентичного по смыслу оригиналу. Данный процесс превращает текст (при сохранении смысловой нагрузки) в уникальный. Отметим, что контент с показателем уникальности ниже 85 \% не выйдет в ТОП поисковой выдачи. Существует два типа рерайта: механический (бесполезный) и адаптированный (полезный). Для научных популяризаторов важен рерайт второго типа, поскольку он связан с адаптацией специализированных текстов для широкой аудитории.

\section{Методы и результаты исследования}

Достоверность данного исследования обеспечивается обширным эмпирическим материалом и системой его изучения. Использовался сравнительный метод, включающий сопоставление различных типов контента, а также метод анализа документов с элементами контент-анализа. В качестве количественных методик оценки эффективности интернет-СМИ в социальной сети «ВКонтакте», мессенджере Telegram были использованы данные аналитических сервисов Telegram Analytics и Livedune. Выбор научно-популярных СМИ осуществлялся на основе данных системы «Медиалогия». В соответствии с рейтингом самых цитируемых медиаресурсов научно-популярной тематики за II квартал 2020 г. ${ }^{1}$ лидерами являются интернет-СМИ Nplus1.ru (индекс цитирования ИЦ - 69,63) и Naked-science.ru (ИЦ - 69,54) (табл. 1), которые и были выбраны для исследования.

Хронологические рамки для контент-анализа сайтов и социальных сетей: с 1 по 31 декабря 2020 года. Массив эмпирических данных был сформирован по хронологическому признаку, включает различные типы контента, представленные на сайте, в социальной сети «ВКонтакте» и мессенджере Teleqram.

Таблица 1

тОП-5 самых цитируемых СМИ научно-популярной тематики, II квартал 2020 г. (01.04.2020 - 30.06.2020)

\begin{tabular}{cccc}
\hline № & Сми & Категория & ИЦ \\
\hline 1. & Nplus1.ru & Интернет & 69,63 \\
2. & Naked-science.ru & Интернет & 69,54 \\
3. & «Наука в Сибири» & Газета & 33,58 \\
4. & Роstnauka.ru & Интернет & 30,67 \\
5. & «Популярная механика» & Журнал & 20,91 \\
\hline
\end{tabular}

Источник: Медиалогия. URL: https://www.mlg.ru/

${ }^{1}$ СМИ научно-популярной тематики - II квартал 2020 года // Медиалогия. URL: https://www.mlg.ru/ratings/media/sectoral/7761/ (дата обращения: 14.02.2021). 
TOP-5 most cited popular science media outlets,

II quarter of $2020(01.04 .2020-30.06 .2020)$

\begin{tabular}{cccc}
\hline No. & Media & Category & Citation index \\
\hline 1. & Nplus1.ru & Internet & 69,63 \\
2. & Naked-science.ru & Internet & 69,54 \\
3. & Science in Siberia & Newspaper & 33,58 \\
4. & Postnauka.ru & Internet & 30,67 \\
5. & Popular Mechanics & Magazine & 20,91 \\
\hline
\end{tabular}

Source: Medialogiya. Retrieved from: https://www.mlg.ru/

Выбранные научно-популярные СМИ специализируются на освещении научно-популярной тематики и имеют свидетельство о регистрации СМИ.

Nplus1.ru (N+1) - научно-популярное издание о том, что происходит в науке, технике и технологиях. Позиционирование издания: «Мы - чуть больше, чем просто наука!». Naked Science (пер. с англ. «С точки зрения науки») - российский научно-популярный электронный журнал, на страницах которого публикуются последние новости науки и техники, видеотрансляции событий и др. Кроме официального сайта, научно-популярные интернет-СМИ представлены на следующих медиаплощадках (табл. 2): социальные сети «ВКонтакте», Facebook, Twitter, Телеграм; RSS-подписка. При этом Nplus1.ru ведет официальную страницу в «Одноклассниках», размещает треки на платформе SoundCloud. Читать статьи Naked-science.ru можно используя AppStore, Google Play, а также смотреть видео на YouTube.

Таблица 2

Подписчики и пользователи Nplus1.ru и Naked Science

\begin{tabular}{cccccccc}
\hline \multirow{2}{*}{ Сми } & Пользова- & \multicolumn{5}{c}{ Подписчики } \\
\cline { 3 - 7 } & тели & «ВКонтакте» & Facebook & Twitter & “Одноклассники» & Telegram & YouTube \\
\hline Nplus1.ru & 2,3 млн & 212 тыс. & 83 тыс. & 28,1 тыс. & 203,1 тыс. & 35,1 тыс. & - \\
$\begin{array}{c}\text { Naked } \\
\text { Science }\end{array}$ & $1,5 \mathrm{млн}$ & 494 тыс. & 50 тыс. & 5,6 тыс. & - & 85,5 тыс. & 53 тыс. \\
\hline
\end{tabular}

Table 2

Nplus1.ru and Naked Science (subscribers and users)

\begin{tabular}{lccccccc}
\hline \multirow{2}{*}{ Media } & \multirow{2}{*}{ Users } & \multicolumn{5}{c}{ Подписчики } \\
\cline { 3 - 7 } & & VKontakte & Facebook & Twitter & Odnoklassniki & Telegram & YouTube \\
\hline $\begin{array}{c}\text { Nplus1.ru } \\
\begin{array}{c}\text { Naked } \\
\text { Science }\end{array}\end{array}$ & $2,3 \mathrm{mln}$ & 212 thous. & 83 thous. & 28,1 thous. & 203,1 thous. & 35,1 thous. & - \\
\hline
\end{tabular}

Анализ позволил выделить три наиболее эффективные медиаплощадки с точки зрения количества подписчиков. Дальнейшее исследование осуществлялось на базе официальных сайтов СМИ, аккаунтов сети «ВКонтакте», мессенджера Telegram. Использование официальных страниц в Facebook является некорректным, так как страница Naked Science была заблокирована и новости с 11.12.2020 г. публиковались в группе Science.

Аудиторию данных научно-популярных СМИ составляют хорошо образованные, умеющие критически думать люди. Количество пользователей в 
месяц у сайта Nplus1.ru - 2,38 млн, у Naked Science - 1,5 млн. Возраст аудитории - 18-55 лет (табл. 3). Основную аудиторию составляют мужчины старше 25 лет.

Таблица 3

Аудитория порталов Nplus1.ru и Naked Science

\begin{tabular}{cccccccc}
\hline \multirow{2}{*}{ Портал } & \multicolumn{3}{c}{ Возраст, лет, \% } & \multicolumn{2}{c}{ Пол, \% } \\
\cline { 2 - 8 } & $\mathbf{1 8 - 2 4}$ & $\mathbf{2 5 - 3 4}$ & $\mathbf{3 5 - 4 4}$ & $\mathbf{4 5 - 5 4}$ & $\mathbf{5 5 +}$ & Муж. & Жен. \\
\hline Nplus1.ru & 11,24 & 27,43 & 21,79 & 14,56 & 24,96 & 58,3 & 41,7 \\
Naked-science.ru & 8,9 & 21,9 & 24,4 & 23,5 & 17,1 & 75,0 & 25,0 \\
\hline
\end{tabular}

Table 3

Audience of the portals Nplus1.ru and Naked Science

\begin{tabular}{cccccccc}
\hline \multirow{2}{*}{ Portal } & \multicolumn{4}{c}{ Age, years, \% } & \multicolumn{2}{c}{ Gender, \% } \\
\cline { 2 - 8 } & $\mathbf{1 8 - 2 4}$ & $\mathbf{2 5 - 3 4}$ & $\mathbf{3 5 - 4 4}$ & $\mathbf{4 5 - 5 4}$ & $\mathbf{5 5 +}$ & Male & Female \\
\hline Nplus1.ru & 11,24 & 27,43 & 21,79 & 14,56 & 24,96 & 58,3 & 41,7 \\
Naked-science.ru & 8,9 & 21,9 & 24,4 & 23,5 & 17,1 & 75,0 & 25,0 \\
\hline
\end{tabular}

Анализ показал, что количество подписчиков Naked Science в аккаунте «ВКонтакте» больше в 2 раза (табл. 4). При этом за декабрь 2020 г. количество опубликованных постов примерно одинаковое (378 и 368), реакция подписчиков на посты Nplus1.ru составляет более 25 тыс. лайков, a Naked Science более 19 тыс. лайков, коэффициент вовлеченности (англ. Engagement Rate, сокр. ER) выше у Nplus1.ru. Однако показатель вовлеченности по охвату постов (англ. Engagement Rate Reach, сокр. ERR) выше у Naked Science (0,64 \%).

Таблица 4

Сравнительный анализ аккаунтов Nplus1.ru и Naked Science в соцсети «ВКонтакте»

\begin{tabular}{lcc}
\hline \multicolumn{1}{c}{ Показатели } & Nplus1.ru & Naked Science \\
\hline Количество подписчиков & 211695 & 494515 \\
Опубликовано постов за период & 378 & 368 \\
Лайков/среднее кол-во лайков на пост & $25166 / 66$ & $19978 / 54$ \\
Комментариев/среднее кол-во комментариев на пост & $2131 / 5$ & $5912 / 16$ \\
Репостов/среднее кол-во репостов на пост & $3798 / 10$ & $3334 / 9$ \\
Охват/среднее кол-во на пост & $5052364 / 13366$ & $4582675 / 12452$ \\
ER/ERR & $0,04 \% / 0,62 \%$ & $0,02 \% / 0,64 \%$ \\
\hline
\end{tabular}

Примечание: здесь и далее в таблицах период 1-31 декабря 2020 г.

Comparative analysis of Nplus1.ru and Naked Science accounts in VKontakte

\begin{tabular}{lcc}
\hline \multicolumn{1}{c}{ Indicators } & Nplus1.ru & Naked Science \\
\hline Number of subscribers & 211695 & 494515 \\
Posts posted for the period & 378 & 368 \\
Likes/average likes on the post & $25166 / 66$ & $19978 / 54$ \\
Comments/average number of comments per post & $2131 / 5$ & $5912 / 16$ \\
Reposts/average number of reposts per post & $3798 / 10$ & $3334 / 9$ \\
Coverage/average number per post & $5052364 / 13366$ & $4582675 / 12452$ \\
ER/ERR & $0,04 \% / 0,62 \%$ & $0,02 \% / 0,64 \%$ \\
\hline
\end{tabular}

Note: here and further in the tables, the period is December 1-31, 2020. 
В настоящее время мессенджер Telegram активно развивается: «в первую неделю января 2021 года Telegram превысил 500 млн активных пользователей» ${ }^{2}$. Сравнительный анализ Telegram-каналов данных интернет-СМИ (табл. 5) проводился с использованием сервиса Telegram Analytics.

\section{Сравнительный анализ Telegram-каналов Nplus1.ru и Naked Science}

\begin{tabular}{lcc}
\hline \multicolumn{1}{c}{ Показатели } & Nplus1.ru & Naked Science \\
\hline Подписчиков на 01.12.2020 & 33747 & 74062 \\
Подписчиков на 31.12.2020 & 34447 & 82435 \\
Постов & 188 (в том числе 4 дайджеста) & 179 (в том числе 28 дайджестов) \\
Просмотров & 1786450 & 2298643 \\
Средний охват 1 поста & 6100 & 11436 \\
Среднее количество постов в день & 9,0 & 6,5 \\
Индекс цитирования & 68,55 & 54,58 \\
Средний ЕRR, \% & 23,0 & 16,0 \\
\hline
\end{tabular}

Comparative analysis of Telegram channels Nplus1.ru and Naked Science

\begin{tabular}{lcc}
\hline \multicolumn{1}{c}{ Indicators } & Nplus1.ru & Naked Science \\
\hline Subscribers as of 01.12.2020 & 33747 & 74062 \\
Subscribers as of 31.12.2020 & 34447 & 82435 \\
Posts & 188 (including 4 digests) & 179 (including 28 digests) \\
Views & 1786450 & 2298643 \\
Average reach of 1 post & 6100 & 11436 \\
Average number of posts per day & 9,0 & 6,5 \\
Citation index & 68,55 & 54,58 \\
Average ERR, \% & 23,0 & 16,0 \\
\hline
\end{tabular}

В Telegram-каналах новости публикуются ежедневно. Nplus1.ru новости публикует шесть раз в установленное время. В воскресенье публикуется дайджест с обзором материалов за неделю (8-9 новостей). На Telegramканале Naked Science выходит 5-9 постов в день, и ежедневно дайджест новостей (9-10 публикаций).

В целом необходимо отметить, что исследуемые интернет-СМИ ведут активное продвижение медиаконтента в Telegram. Naked Science имеет большее количество подписчиков, больший охват и уровень вовлеченности аудитории.

С целью сравнения контента авторы изучили распределение опубликованных материалов по рубрикам (табл. 6, 7), а также провели сравнение с опубликованными постами в социальной сети «ВКонтакте» и Telegram.

В рамках установленного периода на сайтах было опубликовано примерно равное количество новостей (Nplus1.ru - 360 публикаций, Naked Science - 326 публикаций).

\footnotetext{
${ }^{2}$ Telegram: контакт@durov. URL: https://t.me/durov/147 (дата обращения: 14.02.2021).
} 
Таблица 6

Сравнительный анализ контента Nplus1.ru на сайте, в аккаунте во «ВКонтакте» и в Telegram-канале

\begin{tabular}{|c|c|c|c|}
\hline \multirow{2}{*}{ Рубрика } & \multirow{2}{*}{$\begin{array}{c}\text { Кол-во новостей } \\
\text { Сайт } \\
\end{array}$} & \multicolumn{2}{|c|}{ Кол-во постов } \\
\hline & & «ВКонтакте» & Telegram-канал \\
\hline Зоология & 47 & 47 & 30 \\
\hline Оружие & 33 & 33 & 2 \\
\hline Астрономия & 28 & 28 & 18 \\
\hline Космонавтика & 27 & 27 & 18 \\
\hline Медицина & 27 & 27 & 10 \\
\hline Роботы и дроны, гаджеты & 25 & 25 & 10 \\
\hline Физика & 24 & 24 & 9 \\
\hline Биология & 24 & 24 & 15 \\
\hline Коронавирусные хроники & 17 & 17 & 12 \\
\hline Психология & 13 & 13 & 5 \\
\hline Экология и климат & 13 & 13 & 10 \\
\hline Книжная полка & 12 & 12 & 2 \\
\hline Транспорт & 11 & 11 & 5 \\
\hline Авиация & 12 & 12 & - \\
\hline Давайте разберемся & 3 & 1 & - \\
\hline Тесты & 3 & 3 & 3 \\
\hline Блоги & 1 & 1 & 2 \\
\hline Статьи & 20 & 11 & 11 \\
\hline Дайджесты/кол-во новостей & - & $1 / 5$ & $4 / 23$ \\
\hline Реклама (таргет) & - & 15 & 11 \\
\hline Партнерский пост & - & 18 & 11 \\
\hline $\begin{array}{l}\text { Продвижение своих подкастов, } \\
\text { журналов и др. }\end{array}$ & - & 30 & - \\
\hline итого & 360 & 395 & 188 \\
\hline
\end{tabular}

Таблица 6

Comparative analysis of Nplus1.ru content on the site, in VKontakte account and Telegram-channel

\begin{tabular}{|c|c|c|c|}
\hline \multirow{2}{*}{ Heading } & \multirow{2}{*}{$\begin{array}{c}\text { Number of news } \\
\text { Website } \\
\end{array}$} & \multicolumn{2}{|c|}{ Number of posts } \\
\hline & & VKontakte & Telegram-channel \\
\hline Zoology & 47 & 47 & 30 \\
\hline Weapon & 33 & 33 & 2 \\
\hline Astronomy & 28 & 28 & 18 \\
\hline Cosmonautics & 27 & 27 & 18 \\
\hline Medicine & 27 & 27 & 10 \\
\hline Robots and drones, gadgets & 25 & 25 & 10 \\
\hline Physics & 24 & 24 & 9 \\
\hline Biology & 24 & 24 & 15 \\
\hline Coronavirus chronicles & 17 & 17 & 12 \\
\hline Psychology & 13 & 13 & 5 \\
\hline Ecology and climate & 13 & 13 & 10 \\
\hline Bookshelf & 12 & 12 & 2 \\
\hline Transport & 11 & 11 & 5 \\
\hline Aviation & 12 & 12 & - \\
\hline Let's figure it out & 3 & 1 & - \\
\hline Tests & 3 & 3 & 3 \\
\hline Blogs & 1 & 1 & 2 \\
\hline Articles & 20 & 11 & 11 \\
\hline Digests/number of news & - & $1 / 5$ & $4 / 23$ \\
\hline Advertising (target) & - & 15 & 11 \\
\hline Affiliate post & - & 18 & 11 \\
\hline $\begin{array}{l}\text { Promotion of your podcasts, } \\
\text { magazines, etc. }\end{array}$ & - & 30 & - \\
\hline TOTAL & 360 & 395 & 188 \\
\hline
\end{tabular}


Анализ показал тематическое пересечение в шести наиболее популярных рубриках: 1) на сайте Nplus1.ru - «Зоология», «Оружие», «Астрономия», «Космонавтика», «Медицина», «Роботы, дроны, гаджеты»; 2) на сайте Naked Science «Биология», «Оружие и техника», «Медицина», «Космонавтика», «Астрономия», «Ні-Тесһ». Кроме публикации материалов основных тематических рубрик, интернет-СМИ в «ВКонтакте» и Telegram-канале продвигают собственные ресурсы, рекламные материалы, публикуют дайджесты новостей.

При этом тематические рубрики можно условно разделить на блоки в зависимости от информационных потребностей аудитории: познание мира (биология, космонавтика, физика, химия); практическое применение (медицина, темы COVID-2019); безопасность (оружие и техника); саморазвитие (психология); социально значимый контент (экология, медиа); технологический (ІТ-технологии, роботы, дроны); фактологический (история); развлекательный (Sci-Fi).

Изучаемые интернет-СМИ все публикуемые на сайте материалы одновременно репостят в сети «ВКонтакте» и выборочно в Telegram-канале. В соответствии с концепцией четырех уровней кросс-медиа Г. Хейса [17] СМИ используют уровень Bridges (мосты), где медиаконтент, размещенный на одной платформе, является своеобразным «мостиком», побуждающим потребителя перейти на другую медиаплатформу.

Таблица 7

Сравнительный анализ контента Naked Science на официальном сайте, в аккаунте во «ВКонтакте» и в Telegram-канале

\begin{tabular}{|c|c|c|c|}
\hline \multirow{2}{*}{ Рубрика } & \multirow{2}{*}{$\begin{array}{c}\text { Кол-во новостей } \\
\text { Сайт }\end{array}$} & \multicolumn{2}{|c|}{ Кол-во постов } \\
\hline & & ВКонтакте & Telegram-канал \\
\hline Биология & 45 & 44 & 18 \\
\hline Медицина & 44 & 44 & 20 \\
\hline Оружие и техника & 44 & 45 & 12 \\
\hline Космонавтика & 34 & 34 & 15 \\
\hline Астрономия & 23 & 23 & 14 \\
\hline Hi-Tech & 16 & 15 & 8 \\
\hline Психология & 15 & 15 & 10 \\
\hline Прочие науки & 15 & 15 & 9 \\
\hline Медиа & 12 & 12 & 7 \\
\hline Физика & 7 & 7 & 4 \\
\hline История & 6 & 6 & 2 \\
\hline Концепты & 6 & 5 & 3 \\
\hline Sci-Fi & 5 & 4 & 1 \\
\hline Палеонтология & 5 & 4 & 2 \\
\hline С точки зрения науки & 5 & 5 & 3 \\
\hline Видео & 4 & 4 & 3 \\
\hline Геология & 2 & 2 & - \\
\hline Химия & 1 & 1 & - \\
\hline Live & 6 & 18 & 3 \\
\hline Антропология & 2 & 2 & 1 \\
\hline Партнерский пост & 29 & 29 & 9 \\
\hline $\begin{array}{l}\text { Дайджест новостей/ } \\
\text { кол-во новостей }\end{array}$ & - & $28 / 267$ & $28 / 267$ \\
\hline Реклама & - & 13 & 1 \\
\hline $\begin{array}{l}\text { Продвижение своих подкастов, } \\
\text { журналов }\end{array}$ & - & 6 & 6 \\
\hline итого & 326 & 381 & 179 \\
\hline
\end{tabular}


Comparative analysis of Naked Science content on the official website, in VKontakte account and Telegram channel

\begin{tabular}{|c|c|c|c|}
\hline \multirow{2}{*}{ Heading } & \multirow{2}{*}{$\frac{\text { Number of news }}{\text { Website }}$} & \multicolumn{2}{|c|}{ Number of posts } \\
\hline & & VKontakte & Telegram-channel \\
\hline Biology & 45 & 44 & 18 \\
\hline Medicine & 44 & 44 & 20 \\
\hline Weapons and equipment & 44 & 45 & 12 \\
\hline Cosmonautics & 34 & 34 & 15 \\
\hline Astronomy & 23 & 23 & 14 \\
\hline $\mathrm{Hi}$-Tech & 16 & 15 & 8 \\
\hline Psychology & 15 & 15 & 10 \\
\hline Other sciences & 15 & 15 & 9 \\
\hline Media & 12 & 12 & 7 \\
\hline Physcs & 7 & 7 & 4 \\
\hline History & 6 & 6 & 2 \\
\hline Concepts & 6 & 5 & 3 \\
\hline Sci-Fi & 5 & 4 & 1 \\
\hline Paleontology & 5 & 4 & 2 \\
\hline From the point of view of science & 5 & 5 & 3 \\
\hline Video & 4 & 4 & 3 \\
\hline Geology & 2 & 2 & - \\
\hline Chemistry & 1 & 1 & - \\
\hline Live & 6 & 18 & 3 \\
\hline Antropology & 2 & 2 & 1 \\
\hline Affiliate post & 29 & 29 & 9 \\
\hline News digest/number of news & - & $28 / 267$ & $28 / 267$ \\
\hline Advertising & - & 13 & 1 \\
\hline $\begin{array}{l}\text { Promotion of podcasts, } \\
\text { magazines }\end{array}$ & - & 6 & 6 \\
\hline TOTAL & 326 & 381 & 179 \\
\hline
\end{tabular}

В свою очередь, анализ медиатекстов показал, что они проходят процесс рерайтинга и их структура на сайте (табл. 8) и в социальных медиа различается: на сайте - расширенная структура, в соцмедиа - краткий вариант.

Общие элементы медиатекста: рубрика, дата и время публикации, заголовок, иллюстрация, текст новости, ссылки на источники, сведения об авторе, пиктограммы соцсетей. Специфические элементы: 1) Nplus1.ru - 3 материала в рубрике «Читайте также»; 2) Naked Science - сделать закладку новости, блоки «Предыдущая статья», «Следующая статья». Структура медиатекстов аккаунтов «ВКонтакте» (аватар страницы, название ресурса, дата и время публикации, один абзац из основного текста новости, ссылка на новость на сайте, иллюстрация, количество лайков, просмотров, комментариев, репостов, дайджесты новостей со ссылками) и Telegram-каналах (иллюстрация, один абзац из основного текста новости, ссылка на новость на сайте, количество просмотров, время публикации, дайджесты новостей со ссылками) практически совпадает, при этом в Telegram-канале Nplus1.ru присутствует обратная связь с аудиторией.

Необходимо отметить высокую востребованность медиаконтента у аудитории. Например, по данным аналитического сервиса livedune.ru ТОП-3 новости (показатель количество просмотров) Nplus1.ru в «ВКонтакте» стали: «Марсианские пещеры предложили исследовать стаей робособак» (19.12.2020, 
раздел «Роботы и дроны», 36550 просмотров, 301 лайк); «Самый страшный человек» (01.12.2020, раздел «Коронавирус», 32686 просмотров, 137 лайков); «Гаражный «Пфайзер»» (18.12.2020, раздел «Коронавирус», 28924 просмотра, 135 лайков).

Таблица 8

\section{Сравнительный анализ структуры медиатекстов на сайтах Nplus1.ru и Naked Science}

\begin{tabular}{ll}
\hline \multicolumn{1}{c}{ Nplus1.ru } & \multicolumn{1}{c}{ Naked Science } \\
\hline Рубрика. & Рубрика. \\
Дата и время публикации. & Дата и время публикации. \\
Коэффициент сложности материала. & Количество минут прочтения. \\
Заголовок новости. & Сведения об авторе статьи. \\
Иллюстрация. & Количество комментариев. \\
Текст новости. & Количество просмотров. \\
Активные ссылки на источники. & Заголовок новости. \\
Сведения об авторе. & Лид-абзац. \\
Пиктограммы социальных сетей. & Активные хэштеги. \\
Три материала под рубрикой «чтайте также» & Иллюстрация. \\
& Текст новости. \\
& Сделать закладку на новость. \\
& Пиктограммы соцсетей. \\
& Повтор блока с рубрикой и хэштегами \\
\hline
\end{tabular}

Comparative analysis of the structure of media texts on websites Nplus1.ru and Naked Science

\begin{tabular}{ll}
\hline \multicolumn{1}{c}{ Nplus1.ru } & \multicolumn{1}{c}{ Naked Science } \\
\hline Heading. & Heading. \\
Date and time of publication. & Date and time of publication. \\
Material complexity factor. & Number of minutes of reading. \\
News headline. & Information about the author of the article. \\
Illustration. & Number of comments. \\
News text. & Number of views. \\
Active links to sources. & News headline. \\
Information about the author. & Lead paragraph. \\
Social media icons. & Active hashtags. \\
3 articles under the heading "Read also" & Illustration. \\
& News text. \\
& Bookmark news. \\
& Social media icons \\
\hline
\end{tabular}

В свою очередь, у Naked Science в аккаунте «ВКонтакте» лидерами стали: «О награждении сайта Naked Science Литературной премией им. А. Беляева» (24.12.2020, 61066 просмотров, 1185 лайков); пост о возможности скачивания свежего номера журнала (05.12.2020, 27964 просмотров, 72 лайка); дайджет новостей за неделю (20.12.2020, 26054 просмотра, 75 лайков).

Анализ показал, что пользователи Nplus1.ru заинтересовались новостями из рубрик «Космонавтика» и «Коронавирус», а подписчики Naked Science отметили новости по продвижению данного интернет-СМИ.

Следовательно, использование процессов репостинга и рерайтинга в социальных сетях и мессенджерах повышает охват аудитории и вовлечения аудитории в обсуждение медиаконтента. 


\section{Заключение}

В настоящее время существует объективная потребность в масштабном изучении научно-популярной журналистики как направления, активно осваивающего различные каналы дистрибуции медиаконтента. При этом особое внимание необходимо уделить вопросам рерайтинга научно-популярного медиаконтента региональных интернет-СМИ в условиях кросс-медиа. Перспективным направлением исследования является изучение кросс-медийности в контексте оценки эффективности научно-популярной журналистики. Исходя из результатов исследования, можно сделать вывод, что научнопопулярная журналистика в интернете активно развивается в условиях кросс-медиа. Увеличение охвата и поддержание интереса аудитории к научно-популярным интернет-СМИ осуществляется не только за счет актуальной тематики, но и вследствие кроссмедийного использования медиаканалов, репостинга и рерайтинга. Использование трансляции медиаконтента через медиаканалы сделало дистрибуцию и производство единой системой. Это помогает в настройке настройки целевого и таргетированного трафика, обеспечивает обратную связь и позволяет эффективно взаимодействовать одновременно с различными целевыми аудиториями. При этом в условиях кросс-медиа осуществляется трансформация медиатекста, позволяющая представлять его в расширенном и сокращенном формате.

\section{Список литературы}

[1] Тертычный А.А. Быть ли научно-популярной журналистике? // Вестник Воронежского государственного университета. Серия: Филология. Журналистика. 2013. № 2. С. 212-217.

[2] Баканов Р.П. Становление распространения научного знания в России XVIII-XX веков // Информационное поле современной России: практики и эффекты / под ред. Р.П. Баканова. Казань: Казан. ун-т, 2014. С. 22-40.

[3] Парафонова В.И. Научно-популярные журналы в дореволюционный период // Медиаскоп. 2017. Вып. 3. URL: http://www.mediascope.ru/node/897 (дата обращения: 13. 02. 2021).

[4] Суворова С.П. Предметно-функциональные особенности современных российских научно-популярных журналов // Вестник Московского университета. Серия 10. Журналистика. 2013. № 7. С. 128-134.

[5] Дивеева Н.В. Научная популяризация как одна из актуальных задач журналистики в условиях высоких технологий и рыночной экономики // Акценты. Новое в массовой коммуникации. 2012. № 7-8 (110-111). С. 13-16.

[6] Хорольский В.В. Научно-популярная публицистика в информационном обществе: неизбежность бума // Вестник ВГУ. Серия: Филология. Журналистика. 2011. № 3-4. C. 13-24.

[7] Волкова И.И., Гужвий Д.А. Интегративный подход к измерению эффективности контента в новых медиа: постановка проблемы // Вестник Российского университета дружбы народов. Серия: Литературоведение. Журналистика. 2017. Т. 22. № 3. C. 532-543.

[8] Макарова E.E. Научно-популярные сайты в Интернете // Современная журналистика: опыт и перспективы развития: материалы Международной научно-практической конференции. М.: ИГУМО и ИТ, 2012. С. 90-97. 
[9] Пушкарев А.А. Научно-популярная журналистика в Интернете как инструмент развития научно-технического прогресса Российской Федерации // Идеи и новации. 2016. № 3(6). С. 91-97.

[10] Сынбулатова A.P. Специфика научно-популярной журналистики о природе на мультимедийных ресурсах Рунета // Медиасреда. 2015. № 10. С. 63-70.

[11] Суворова С.П. Журналистика научная и научно-популярная: особенности предметной области, функций, задач // Вестник Московского университета. Серия: Журналистика. 2009. № 6. С. 14-23.

[12] Поповеи Л.А. Научно-популярная журналистика: развлечение или просвещение // Век информации. 2018. Т. 1. № 2. С. 124-125.

[13] Женченко М. Эволюция терминов «мультимедиа», «кросс-медиа», «трансмедиа» в развитии цифрового сторителлинга // Studia medioznawcze. 2016. No. 4. Pp. 113-119.

[14] Любановская Ю.О. Кросс-медийность в аспекте конфликта региональных медиаинтересов // Век информации. 2018. № 2-2. С. 264-265.

[15] Зайщев М.Л. Явления трансмедийности в массовом информационном процессе // Журнал Белорусского государственного университета. Журналистика. Педагогика. 2020. № 1. С. 16-20.

[16] Davidson D. Cross-Media communications: An introduction to the art of creating integrated media experiences. Pittsburgh: ETC Press, 2010. 294 p.

[17] Hayes G. Cross-media // Personalizemedia: weblog by Gary Hayes. URL: http://www.personalizemedia.com/ articles/cross-media/ (дата обращения: 11.03.2021).

[18] Мультимедийная журналистика / под общ. ред. А.Г. Качкаевой, С.А. Шомовой. М.: Изд. дом Высшей школы экономики, 2017.

[19] Пащенко Н.А. Кроссмедийность в трэвел-журналистике (на примере программы ТК ВЕТТА «Доступный Урал») // Студент и наука (гуманитарный цикл). 2019. Магнитогорск: Изд-во МГТУ, 2019. С. 673-679.

[20] Калинина Л.В. Вербальная конкуренция в пространстве Интернета: реклама, рерайт, репост // Вестник Вятского государственного гуманитарного университета. 2014. № 3. С. $80-88$.

\section{References}

[1] Tertychnyj, A.A. (2013). Should there be popular science journalism? Vestnik VSU. Series: Philology. Journalism, (2), 212-217. (In Russ.)

[2] Bakanov, R.P. (2014). Formation of the dissemination of scientific knowledge in Russiain the 18th-20th centuries. Information Field of Modern Russia: Practices and Effects (pp. 22-40). Kazan, KU Publ. (In Russ.)

[3] Parafonova, V.I. (2017). Popular science magazines in the pre-revolutionary period. Mediascope (issue 3). (In Russ.) Retrieved February 12, 2021, from http://www.mediascope.ru/node/897

[4] Suvorova, S.P. (2013). Scientific educational topics in modern press. Vestnik Moskovskogo universiteta. Seriya 10. Zhurnalistika, (7), 128-134. (In Russ.)

[5] Diveeva, N.V. (2012). Scientific popularization as one of the urgent tasks of journalism in the context of high technologies and market economy. Accents. New in Mass Communication, 7-8(110-111), 13-16. (In Russ.)

[6] Horolskij, V.V. (2011). Popular science journalism in the information society: The inevitability of a boom. Vestnik VSU. Series: Philology. Journalism, (3-4), 13-24. (In Russ.)

[7] Volkova, I.I., \& Guzhvij, D.A. (2017). Integrated approach to the measurement of content efficiency in new media: The setting of the problem. RUDN Journal of Studies in Literature and Journalism, 22(3), 532-543. (In Russ.)

[8] Makarova, E.E. (2012). Popular science sites on the Internet. Modern Journalism: Experience and Development Prospects: Materials of the International Scientific and Practical Conference (pp. 90-97). Moscow, IGUMO \& IT Publ. (In Russ.) 
[9] Pushkarev, A.A. (2016). Popular science journalism on the Internet as a tool for the development of scientific and technological progress in the Russian Federation. Ideas and Innovations, 6(3), 91-97. (In Russ.)

[10] Synbulatova, A.R. (2015). Specificity of popular science journalism about nature on the multimedia resources of the Runet. Mediasreda, (10), 63-70. (In Russ.)

[11] Suvorova, S.P. (2009). Scientific and popular science journalism: Features of the subject area, functions, tasks. Vestnik Moskovskogo Universiteta. Seriya 10. Zhurnalistika, (6), 14-23. (In Russ.)

[12] Popovec, L.A. (2018). Popular science journalism: Entertainment or education? The Age of Information, 1(2), 124-125. (In Russ.)

[13] Zhenchenko, M. (2016). Evolution of the terms "multimedia", "cross-media", "transmedia" in the development of digital storytelling. Media Studies, (4), 113-119. (In Russ.)

[14] Ljubanovskaja, J.O. (2018). Cross-media coverage in the aspect of the conflict of regional media interests. The Age of Information, (2-2), 264-265. (In Russ.)

[15] Zajcev, M.L. (2020). Phenomena of transmedia in the mass information process. Journal of the Belarusian State University. Journalism and Pedagogics, (1), 16-20. (In Russ.)

[16] Davidson, D. (2010). Cross-media communications: An introduction to the art of creating integrated media experiences. Carnegie Mellon University Pittsburgh: ETC Press.

[17] Hayes, G. (2006). Cross-media in Personalizemedia: Weblog by Gary Hayes. Retrieved March 11, 2021, from http://www.personalizemedia.com/articles/cross-media/

[18] Kachkaeva, A.G., \& Shomova, S.A. (Eds.) (2017). Multimedia journalism. Moscow, HSE Publishing House. (In Russ.)

[19] Pashhenko, N.A. (2019). Crossmedia in travel journalism (on the example of the program TC VETTA “Accessible Ural”). Student and Science (Humanities Cycle) (pp. 673-679). Magnitogorsk, MGTU Publ. (In Russ.)

[20] Kalinina, L.V. (2014). Verbal competition in the Internet space: Advertising, rewriting, repost. Herald of Vyatka State University, (3), 80-88. (In Russ.)

\section{Сведения об авторах:}

Лободенко Лидия Камиловна, доктор филологических наук, директор, Институт медиа и социально-гуманитарных наук, профессор, кафедра журналистики, рекламы и связей с общественностью, Южно-Уральский государственный университет (национальный исследовательский университет).

Давлетшина Елена Васильевна, начальник, управление медиакоммуникаций и мониторинга, доцент, кафедра журналистики, рекламы и связей с общественностью, Южно-Уральский государственный университет (национальный исследовательский университет).

\section{Bio notes:}

Lidiya K. Lobodenko, Doctor of Philology, Head of the Institute of Media, Social Sciences and Humanities, Professor, Department of Journalism, Advertising, and Public Relations, South Ural State University (National Research University).

Elena V. Davletshina, Head of the Media Relations and Monitoring Department, Associate Professor, Department of Journalism, Advertising, and Public Relations, South Ural State University (National Research University). 